Acta Crystallographica Section C

Crystal Structure

Communications

ISSN 0108-2701

\section{Twinning by merohedry in cyclo- hexanone oxime: a revised structure}

\author{
Martin Lutz, ${ }^{\mathrm{a} *}$ Anthony L. Spek, ${ }^{a}$ Reza Dabirian, \\ Cornelis A. van Walree ${ }^{b}$ and Leonardus W. Jenneskens ${ }^{b}$
}

${ }^{a}$ Bijvoet Centre for Biomolecular Research, Department of Crystal and Structural Chemistry, Utrecht University, Padualaan 8, 3584 CH Utrecht, The Netherlands, and ${ }^{\mathbf{b}}$ Debye Institute, Department of Physical Organic Chemistry, Utrecht University, Padualaan 8, $3584 \mathrm{CH}$ Utrecht, The Netherlands

Correspondence e-mail:m.lutz@chem.uu.nl

\section{Received 11 December 2003}

Accepted 17 December 2003

Online 17 January 2004

The crystal structure of cyclohexanone oxime, $\mathrm{C}_{6} \mathrm{H}_{11} \mathrm{NO}$, was reported as severely disordered in the trigonal non-centrosymmetric space group P3 [Olivato, Ribeiro, ZukermanSchpector \& Bombieri (2001). Acta Cryst. B57, 705-713]. Reinvestigation of the crystal structure as twinned by merohedry in the trigonal centrosymmetric space group $P \overline{3}$, with a twofold rotation about [001] as twin law, resulted in a well ordered structure and low $R$ values. The asymmetric unit contains three independent molecules, existing as a hydrogen-bonded trimer, having an $R_{3}^{3}(9)$ graph set.

\section{Comment}

The oxime moiety can both donate and accept hydrogen bonds, which makes it a very interesting building block in supramolecular chemistry (Bertolasi et al., 1982; Chertanova et al., 1994). Most oximes crystallize as dimers (e.g. DLcarvoxime; Oonk \& Kroon, 1976), but there are also cases of trimeric (e.g. acetoxime; Bierlein \& Lingafelter, 1951), tetrameric [e.g. (E)-benzaldehyde oxime; Jerslev, 1983] and polymeric (e.g. $2 H$-benzocyclobuten-1-one oxime; Viossat et al., 1986) motifs. One of the trimeric examples is cyclohexanone oxime, (I). The reported crystal structure was refined with a disorder model and final disagreement factors were unexpectedly high (Olivato et al., 2001). As part of our studies of oximes in the solid state (Marsman et al., 2000), we decided to re-examine this crystal structure using a new data collection.

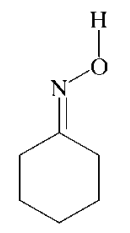

(I)

Our unit cell has a hexagonal metric, which is consistent with the literature data. A first inspection of the diffraction data shows that for the Laue groups $\overline{3}$ and $6 / m$, the merging $R$

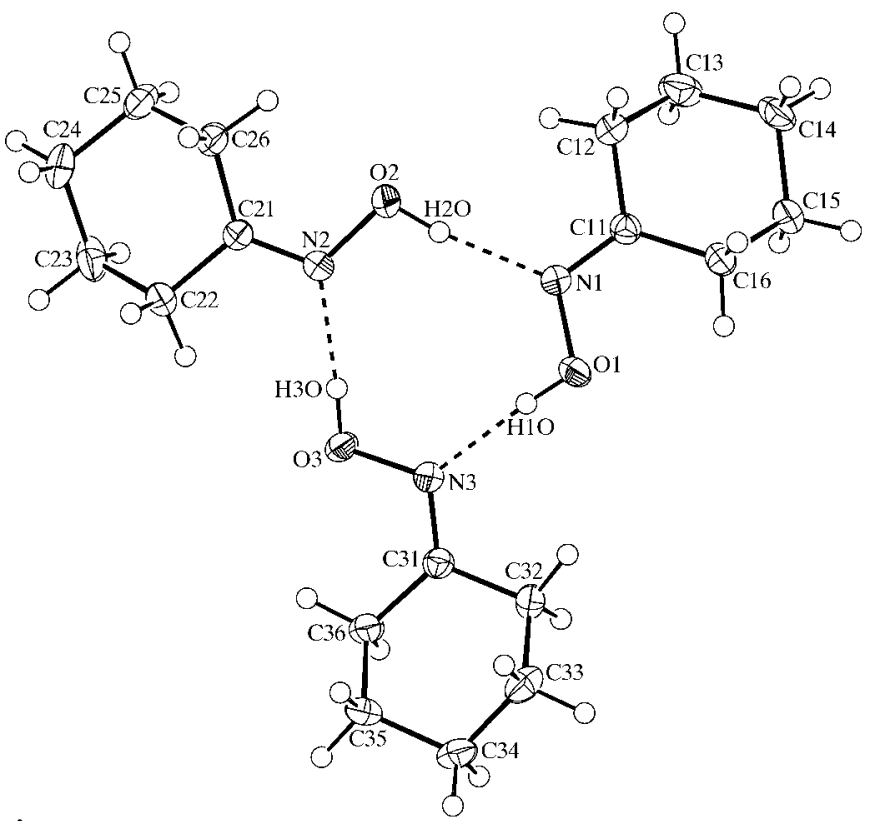

Figure 1

The three independent residues of (I), linked by hydrogen bonds into a trimeric structure. Displacement ellipsoids are shown at the $50 \%$ probability level.

values ( 0.0514 and 0.0542 , respectively) are very similar. We interpret this similarity as a strong indication of twinning. Because all reflections in the diffraction images have been indexed and no splitting of reflections is observed, the twinning must be (pseudo)merohedral.

Systematic space-group extinctions are not present. In contrast to the previously determined structure, which was reported in space group $P 3$, the present structure was solved in the centrosymmetric space group $P \overline{3}$. However, the refinement converges at high $R$ values, with residual density in the difference Fourier map. A coset decomposition (Flack, 1987) of point group $6 / m$ with respect to $\overline{3}$ gives

$$
\left\{E ; 3 ; 3^{2} ; i ; \overline{3} ; \overline{3}^{5}\right\}+\left\{6 ; 2 ; 6^{5} ; \overline{6} ; m ; \overline{6}^{5}\right\} .
$$

Any element of the second coset might be the twin operation. It transpires that the twofold rotation about [001] or, correspondingly, the mirror perpendicular to [001] are the correct merohedral twin operations (see also Giacovazzo, 2002). This result can also be obtained using the program ROTAX (Cooper et al., 2002) or the TWINROTMAT routine of PLATON (Spek, 2003). Both programs use the difference between observed and calculated structure factors, i.e. $I_{\text {obs }}>>I_{\text {calc }}$, to suggest the twin law. After implementing the twin law in the SHELXL97 refinement (Herbst-Irmer \& Sheldrick, 1998), good $R$ values and a clean residual-density map are achieved. The value of the twin fraction refined to 0.5295 (14).

As a further proof for the reported revision, we refined our model and twin law against the structure factors deposited by Olivato et al. (2001). This refinement, (II), leads to essentially the same result, i.e. no disorder, low $R$ values, a clean residualdensity map and a twin fraction of 0.4515 (13). The minor differences, namely a $0.3 \%$ smaller unit-cell volume and 


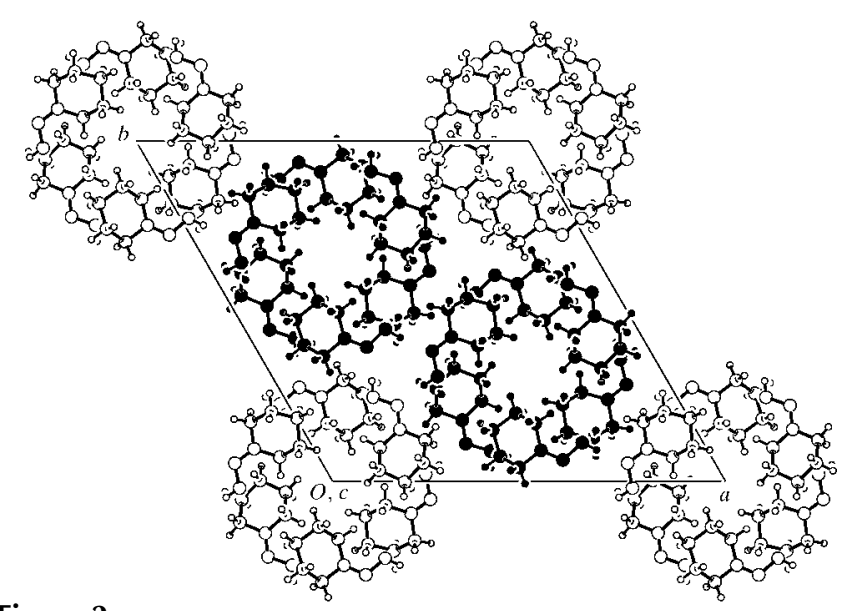

Figure 2

A view along the $c$ axis. Residues 1 and 2 are solid, while residue 3 is unfilled.

slightly smaller displacement parameters, can be explained by the use of different crystals and different measurement temperatures (100 versus $110 \mathrm{~K})$.

The asymmetric unit consists of three independent molecules of (I), with very similar bond lengths and angles (Table 1). The six-membered rings are in a chair conformation, which is slightly distorted because of the presence of the double bond of the oxime group. The $\mathrm{N}-\mathrm{O}$ bond is eclipsed with the $\mathrm{C} 1-\mathrm{C} 6$ bond of the six-membered ring, with torsion angles of $1.8(2), 1.3(2)$ and $-2.8(2)^{\circ}$, respectively.

The three independent molecules are linked by intermolecular hydrogen bonds into a trimeric structure (Fig. 1 and Table 2). Thereby, the oxime $\mathrm{O}$ atoms act as hydrogen-bond donors and the $\mathrm{N}$ atoms as acceptors, thus generating an $R_{3}^{3}(9)$ graph set (Bernstein et al., 1995). The oxime groups have an anti conformation, with $\mathrm{C}-\mathrm{N}-\mathrm{O}-\mathrm{H}$ torsion angles of $-169.5(11), 176.8(10)$ and $172.3(15)^{\circ}$, respectively. The trimer has no crystallographic symmetry, because two of the molecules have the same chair conformation (residues 1 and 2 ), while one molecule has an inverted-chair conformation

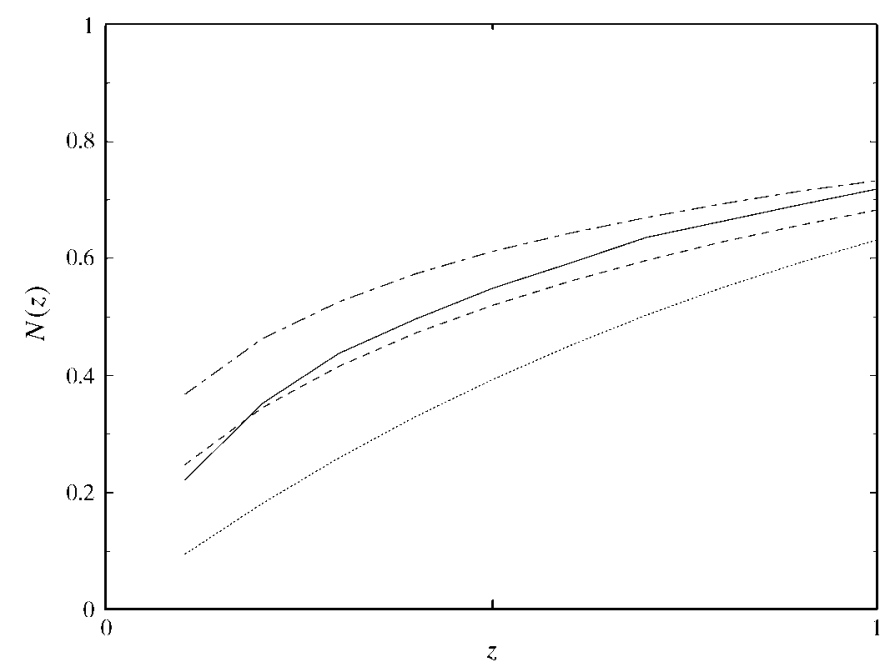

Figure 3

A cumulative $N(z)$ probability distribution (observed data: solid line; acentric: dotted line; centric: dashed line; hypercentric: dot-dashed line).

(residue 3). These inverted conformations are best described by a ring-puckering analysis (Cremer \& Pople, 1975); residues 1 and 2 have $\theta$ values of 170.9 (2) and $171.06(19)^{\circ}$, and $\varphi$ values of $352.2(13)$ and $349.6(13)^{\circ}$, respectively. The inverted conformation of residue 3 results in a $\theta$ value of $9.30(19)^{\circ}$ and a $\varphi$ value of $180.4(12)^{\circ}$.

The cyclohexane rings of residues 1 and 2 are arranged about the threefold axis at $\frac{1}{3}, \frac{2}{3}, z$. The cyclohexane rings of residue 3 are located about the $\overline{3}$ site at $0,0,0$ (Fig. 2). There are small solvent-accessible channels in the $z$ direction, which amount to $2 \times 25 \AA^{3}$ per unit cell at the threefold axes and to $18 \AA^{3}$ per unit cell at $\overline{3}$. In total, $2.3 \%$ of the unit cell is void, leading to a packing index (Kitajgorodskij, 1973) of only $67.3 \%$ and a low density of $1.160 \mathrm{Mg} \mathrm{m}^{-3}$. These channels might also explain the diffuse scattering reported by Olivato $e t$ $a l$. (2001) and the slightly enlarged displacement ellipsoids of the present structure.

Averaging of the 3 and $\overline{3}$ sites leads to a hexagonal subcell with a volume of $\frac{1}{3}$ and an $a$ axis of $12.115 \AA$. This subcell has been reported by Olivato et al. (2001) and Okaya et al. (1956). Indeed, we find this pseudo-translational symmetry in a hypercentric behaviour of the cumulative $N(z)$ probability distribution of the observed twinned data (Fig. 3); $\left\langle E^{2}-1\right\rangle$ is 0.982. Based on calculated untwinned structure factors, the average intensity of reflections $h k l(h+2 k=3 n)$ is 30464.5 , and for all other reflections it is 6798.4.

\section{Experimental}

Suitable single crystals of (I) were grown by sublimation of the commercially obtained material (Fluka Chemie $\mathrm{GmbH}$ ) at a temperature of $333 \mathrm{~K}$ and a pressure of $0.97 \mathrm{mbar}(1 \mathrm{mbar}=100 \mathrm{~Pa})$. The preparation of the crystals used for refinement (II) is described by Olivato et al. (2001).

\section{Refinement (I)}

Crystal data

$$
\begin{aligned}
& \mathrm{C}_{6} \mathrm{H}_{11} \mathrm{NO} \\
& M_{r}=113.16 \\
& \text { Trigonal, } P \overline{3} \\
& a=20.9830(2) \AA \\
& c=7.6436(1) \AA \\
& V=2914.50(5) \AA^{3} \\
& Z=18 \\
& D_{x}=1.160 \mathrm{Mg} \mathrm{m}^{-3}
\end{aligned}
$$

\section{Data collection}

Nonius KappaCCD diffractometer $\varphi$ and $\omega$ scans

52734 measured reflections 4446 independent reflections 3695 reflections with $I>2 \sigma(I)$

\section{Refinement}

Refinement on $F^{2}$ $R\left[F^{2}>2 \sigma\left(F^{2}\right)\right]=0.037$ $w R\left(F^{2}\right)=0.097$ $S=1.03$

4446 reflections 230 parameters

$\mathrm{H}$ atoms treated by a mixture of independent and constrained refinement
Mo $K \alpha$ radiation

Cell parameters from 61960 reflections $\theta=1.9-27.5^{\circ}$ $\mu=0.08 \mathrm{~mm}^{-1}$ $T=110$ (2) K Block, colourless $0.30 \times 0.21 \times 0.15 \mathrm{~mm}$

$$
\begin{aligned}
& R_{\text {int }}=0.051 \\
& \theta_{\text {max }}=27.5^{\circ} \\
& h=-27 \rightarrow 27 \\
& k=-27 \rightarrow 27 \\
& l=-9 \rightarrow 9
\end{aligned}
$$

$$
\begin{gathered}
w=1 /\left[\sigma^{2}\left(F_{o}^{2}\right)+(0.0519 P)^{2}\right. \\
+0.3836 P] \\
\text { where } P=\left(F_{o}^{2}+2 F_{c}^{2}\right) / 3 \\
(\Delta / \sigma)_{\max }=0.002 \\
\Delta \rho_{\max }=0.24 \mathrm{e}^{-3} \\
\Delta \rho_{\min }=-0.21 \mathrm{e}^{-3}
\end{gathered}
$$


Table 1

Selected geometric parameters $\left(\AA,^{\circ}\right)$ for (I).

\begin{tabular}{lclc}
\hline $\mathrm{O} 1-\mathrm{N} 1$ & $1.4101(15)$ & $\mathrm{N} 2-\mathrm{C} 21$ & $1.2757(19)$ \\
$\mathrm{N} 1-\mathrm{C} 11$ & $1.2782(18)$ & $\mathrm{O} 3-\mathrm{N} 3$ & $1.4126(15)$ \\
$\mathrm{O} 2-\mathrm{N} 2$ & $1.4112(15)$ & $\mathrm{N} 3-\mathrm{C} 31$ & $1.2859(19)$ \\
& & & \\
$\mathrm{C} 11-\mathrm{N} 1-\mathrm{O} 1$ & $113.58(11)$ & $\mathrm{N} 2-\mathrm{C} 21-\mathrm{C} 22$ & $117.50(13)$ \\
$\mathrm{N} 1-\mathrm{C} 11-\mathrm{C} 16$ & $125.68(13)$ & $\mathrm{C} 31-\mathrm{N} 3-\mathrm{O} 3$ & $113.06(12)$ \\
$\mathrm{N} 1-\mathrm{C} 11-\mathrm{C} 12$ & $117.79(13)$ & $\mathrm{N} 3-\mathrm{C} 31-\mathrm{C} 36$ & $125.78(13)$ \\
$\mathrm{C} 21-\mathrm{N} 2-\mathrm{O} 2$ & $113.49(12)$ & $\mathrm{N} 3-\mathrm{C} 31-\mathrm{C} 32$ & $117.16(14)$ \\
$\mathrm{N} 2-\mathrm{C} 21-\mathrm{C} 26$ & $125.97(13)$ & & \\
& & & \\
$\mathrm{O} 1-\mathrm{N} 1-\mathrm{C} 11-\mathrm{C} 16$ & $1.8(2)$ & $\mathrm{N} 2-\mathrm{C} 21-\mathrm{C} 22-\mathrm{C} 23$ & $-131.58(15)$ \\
$\mathrm{N} 1-\mathrm{C} 11-\mathrm{C} 12-\mathrm{C} 13$ & $-132.61(16)$ & $\mathrm{O} 3-\mathrm{N} 3-\mathrm{C} 31-\mathrm{C} 36$ & $-2.8(2)$ \\
$\mathrm{O} 2-\mathrm{N} 2-\mathrm{C} 21-\mathrm{C} 26$ & $1.3(2)$ & $\mathrm{N} 3-\mathrm{C} 31-\mathrm{C} 32-\mathrm{C} 33$ & $133.04(15)$ \\
\hline
\end{tabular}

Table 2

Hydrogen-bonding geometry $\left(\AA,^{\circ}\right)$ for $(\mathrm{I})$.

\begin{tabular}{lllll}
\hline$D-\mathrm{H} \cdots A$ & $D-\mathrm{H}$ & $\mathrm{H} \cdots A$ & $D \cdots A$ & $D-\mathrm{H} \cdots A$ \\
\hline O1-H1O $\cdots \mathrm{N} 3$ & $0.884(18)$ & $1.884(18)$ & $2.7653(17)$ & $175.3(16)$ \\
$\mathrm{O} 2-\mathrm{H} 2 \mathrm{O} \cdots \mathrm{N} 1$ & $0.908(17)$ & $1.861(17)$ & $2.7632(15)$ & $171.9(15)$ \\
$\mathrm{O} 3-\mathrm{H} 3 \mathrm{O} \cdots \mathrm{N} 2$ & $0.89(2)$ & $1.89(2)$ & $2.7834(17)$ & $176.2(18)$ \\
\hline
\end{tabular}

Refinment (II), using the structure factors of Olivateo et al. (2001)

$$
\begin{aligned}
& \text { Crystal data } \\
& \mathrm{C}_{6} \mathrm{H}_{11} \mathrm{NO} \\
& M_{r}=113.16 \\
& \text { Trigonal, } P \overline{3} \\
& a=20.9830(3) \AA \\
& c=7.6210(1) \AA \\
& V=2905.88(7) \AA^{3} \\
& Z=18 \\
& D_{x}=1.164 \mathrm{Mg} \mathrm{m}^{-3}
\end{aligned}
$$

\section{Data collection}

Nonius CAD-4 diffractometer $\varphi$ and $\omega$ scans

12992 measured reflections

4440 independent reflections

3993 reflections with $I>2 \sigma(I)$

\section{Refinement}

Refinement on $F^{2}$

$R\left[F^{2}>2 \sigma\left(F^{2}\right)\right]=0.034$

$w R\left(F^{2}\right)=0.089$

$S=1.04$

4440 reflections

230 parameters

$\mathrm{H}$ atoms treated by a mixture of independent and constrained refinement

For refinement (I), a first data set was collected with a rotation angle of $1^{\circ}$ and an exposure time of $40 \mathrm{~s}$ per frame ( $248 \varphi$ scans and $433 \omega$ scans). These data were integrated with the $H K L 2000$ package (Otwinowski \& Minor, 1997), resulting in 49597 reflections in a $\theta$ range of $1.9-27.5^{\circ}$. Cell parameters were taken from a post-refinement of these data. A second data set of (I) was collected with a rotation angle of $1^{\circ}$ and an exposure time of $10 \mathrm{~s}$ per frame (101 $\varphi$ scans and $28 \omega$ scans). These data were integrated with the EvalCCD package (Duisenberg et al., 2003), resulting in 3137 reflections in a $\theta$ range of $1.9-15.0^{\circ}$. Both data sets were scaled and merged with the program SORTAV (Blessing, 1997). For details of the data collection of (II), see Olivato et al. (2001). For refinements (I) and (II), H atoms attached to $\mathrm{O}$ atoms were refined freely, with isotropic displacement parameters. All remaining $\mathrm{H}$ atoms were placed in idealized positions $(\mathrm{C}-\mathrm{H}=0.99-1.00 \AA)$ and constrained to ride on their parent atoms, with $U_{\text {iso }}(\mathrm{H})$ values of $1.2 U_{\text {eq }}(\mathrm{C})$.

For refinement (I), data collection: COLLECT (Nonius, 1999); cell refinement: HKL2000 (Otwinowski \& Minor, 1997); data reduction: HKL2000 and EvalCCD (Duisenberg et al., 2003); program(s) used to solve structure: SHELXS97 (Sheldrick, 1997); program(s) used to refine structure: SHELXL97 (Sheldrick, 1997); molecular graphics: PLATON (Spek, 2003).

For refinement (II), cell refinement: HKL2000 (Otwinowski \& Minor, 1997); data reduction: HKL2000; program(s) used to solve structure: SHELXS97 (Sheldrick, 1997); program(s) used to refine structure: SHELXL97 (Sheldrick, 1997).

This work was supported by the Council for Chemical Sciences of the Netherlands Organization for Scientific Research (CW-NWO).

Supplementary data for this paper are available from the IUCr electronic archives (Reference: FG1726). Services for accessing these data are described at the back of the journal.

\section{References}

Bernstein, J., Davis, R. E., Shimoni, L. \& Chang, N.-L. (1995). Angew. Chem. Int. Ed. Engl. 34, 1555-1573.

Bertolasi, V., Gilli, G. \& Veronese, A. C. (1982). Acta Cryst. B38, 502-511. Bierlein, T. K. \& Lingafelter, E. C. (1951). Acta Cryst. 4, 450-453.

Blessing, R. H. (1997). J. Appl. Cryst. 30, 421-426.

Chertanova, L., Pascard, C. \& Sheremetev, A. (1994). Acta Cryst. B50, 708716.

Cooper, R. I., Gould, R. O., Parsons, S. \& Watkin, D. J. (2002). J. Appl. Cryst. 35, 168-174.

Cremer, D. \& Pople, J. A. (1975). J. Am. Chem. Soc. 97, 1354-1358.

Duisenberg, A. J. M., Kroon-Batenburg, L. M. J. \& Schreurs, A. M. M. (2003). J. Appl. Cryst. 36, 220-229.

Flack, H. D. (1987). Acta Cryst. A43, 564-568.

Giacovazzo, C. (2002). Fundamentals of Crystallography, 2nd ed., edited by C. Giacovazzo, pp. 227-236. Oxford University Press.

Herbst-Irmer, R. \& Sheldrick, G. M. (1998). Acta Cryst. B54, 443-449.

Jerslev, B. (1983). Acta Cryst. C39, 1447-1454.

Kitajgorodskij, A. I. (1973). Molecular Crystals and Molecules. New York: Academic Press.

Marsman, A. W., van Walree, C. A., Havenith, R. W. A., Jenneskens, L. W., Lutz, M., Spek, A. L., Lutz, E. T. G. \& van der Maas, J. H. (2000). J. Chem. Soc. Perkin Trans. 2, pp. 501-510.

Nonius (1999). COLLECT. Nonius BV, Delft, The Netherlands.

Okaya, Y., Shimada, A. \& Nitta, I. (1956). Bull. Chem. Soc. Jpn, 29, 210-212.

Olivato, P. R., Ribeiro, D. S., Zukerman-Schpector, J. \& Bombieri, G. (2001). Acta Cryst. B57, 705-713.

Oonk, H. A. J. \& Kroon, J. (1976). Acta Cryst. B32, 500-504.

Otwinowski, Z. \& Minor, W. (1997). Methods in Enzymology, Vol. 276, Macromolecular Crystallography, Part A, edited by C. W. Carter Jr \& R. M. Sweet, pp. 307-326. New York: Academic Press.

Sheldrick, G. M. (1997). SHELXS97 and SHELXL97. University of Göttingen, Germany.

Spek, A. L. (2003). J. Appl. Cryst. 36, 7-13.

Viossat, B., Rodier, N., Andrieux, J. \& Plat, M. (1986). Acta Cryst. C42, 824825 . 